\title{
UMA ESPÉCIE NOVA DE SCHWARZULA DA AMAZÔNIA (HYMENOPTERA, APIDAE, MELIPONINI)
}

\author{
João M. F. Camargo ${ }^{1,2}$ \\ Silvia R. M. Pedro ${ }^{1}$
}

\begin{abstract}
A NEW SPECIES OF SCHWARZULA FROM AMAZON (HYMENOPTERA, APIDAE, MELIPONINI). Schwarzula coccidophila sp. nov., a tiny Amazonian stingless bee, that attends scale insects (Cryptostigma Ferris, 1922, Coccidae) in its nest, is described. It is distinguished from Schwarzula timida (Silvestri, 1902), the only other species of the genus, mainly by the malar area longer than diameter of $3^{\text {rd }}$ flagellomere, and the denser plumose pilosity. Additional records of $S$. timida is presented.
\end{abstract}

KEYWORDS. Neotropical, Schwarzula, taxonomy, mutualism, Coccidae.

\section{INTRODUÇÃO}

Em coletas ao longo da região do rio Negro, Amazonas, em 1980, 1999 e 2001, tevese a oportunidade de estudar muitos ninhos de uma espécie nova de abelha do gênero Schwarzula Moure, 1946, que vive em associação mutualística com cochonilhas do gênero Cryptostigma Ferris, 1922, Coccidae, das quais obtém cera e secreções adocicadas (CAMARgo \& Pedro, 2002).

Formaliza-se a descrição da espécie nova e apresenta-se dados novos sobre a distribuição geográfica de Schwarzula timida (Silvestri, 1902), única espécie do gênero até agora conhecida.

Medidas (em milímetros) e forma das descrições seguem CAMARgo \& Moure (1994). Tergos e esternos metassomáticos são indicados em numerais romanos. Os exemplares examinados estão depositados nas seguintes instituições: Departamento de Biologia da Faculdade de Filosofia, Ciências e Letras de Ribeirão Preto, Universidade de São Paulo, Ribeirão Preto, coleção J. M. F. Camargo (RPSP); Instituto Nacional de Pesquisas da Amazônia, Manaus (INPA); Carnegie Museum of Natural History, Pittsburgh (CMNH); Michigan State University Collection, East Lansing (MSUC) e Snow Entomological Museum, University of Kansas, Lawrence (SEMC).

1. Departamento de Biologia, Faculdade de Filosofia, Ciências e Letras de Ribeirão Preto, Universidade de São Paulo, Av. Bandeirantes, 3900, 14040-901, Ribeirão Preto, SP, Brasil.

2. Pesquisador do CNPq. 


\section{Schwarzula coccidophila sp. nov.}

(Figs. 1, 2, 4, 5, 7-13)

Schwarzula aff. timida; CAMARGO, 1988:363.

Schwarziana flavornata Cruz-LANDim \& Mota, 1990:587; MотA, 1992:321. N. nudum.

Schwarzula flavornata; CRUz-LANDIM \& MotA, 1990:588. N. nudum.

Scwarzula [sic] flavornata; МотА, 1992:320. N. nudum.

Nota. Reconhecemos esta espécie em 1980, quando estudamos, pela primeira vez, um ninho na região da foz do rio Daraã, médio rio Negro. Etiquetamos os espécimens (RPSP) como Schwarzula flavornata. Referência à esta espécie foi, inadvertidamente, feita por CRUZ-LANDIM \& MotA (1990), erroneamente subordinada ao gênero Schwarziana Moure, 1943 e por Mота (1992). Agora, a espécie é formalmente descrita com o nome de S. coccidophila, em referência ao seu peculiar modo de vida.

Diagnose. Schwarzula coccidophila difere de $S$. timida pela área malar cerca de 1,5 vez mais longa que o diâmetro do $3^{\circ}$ flagelômero (em $S$. timida, o comprimento da área malar apenas iguala-se ao diâmetro do $3^{\circ}$ flagelômero) e pela pilosidade plumosa relativamente densa e mais abundante na face e lados do propódeo.

Operária (figs. 1, 2, 4, 5, 12). Dimensões (tab. I). Integumento preto; âmbar-escuro apenas os tarsômeros de todos os pares de pernas, basitarsos anteriores e médios, mancha na metade apical do basitarso posterior, ápice da tíbia média, labro e mandíbulas, exceto côndilos, três artículos apicais do flagelo, base do escapo, e uma faixa no terço apical do clípeo. Tégulas fuscas com áreas mais claras no centro e borda posterior. Asas hialinas iridescentes; pterostigma e nervuras méleo-escuras.

Cerdas eretas amarelo-pálidas na cabeça, mesoscuto, tergos metassomáticos, basitarsos, tarsômeros e tíbias de todas as pernas; tíbia posterior com algumas cerdas ferrugíneo-fuscas intercaladas na margem posterior; ferrugíneas na face interna do basitarso e tíbia posteriores; esbranquiçadas na porção ventral do tórax e metassoma e no tergo VI. Microtríquias nas membranas alares, ferrugíneo-fuscas. Pilosidade plumosa decumbente, intercalada às cerdas eretas, relativamente densa, esbranquiçada, no clípeo e face até aproximadamente a altura do sulco frontal, área malar, no terço mediano justaorbital das genas, lobos pronotais e tergo VI; mais longa e fina nos mesepisternos e metepisternos; abundante nos lados do propódeo; no escutelo um pouco mais fina e esparsa. Disco do mesoscuto com pilosidade decumbente, simples, muito fina e rala, deixando à mostra o integumento brilhante. Comprimento das cerdas do clípeo, fronte, escapo, vértice, mesepisterno, mesoscuto e escutelo (tab. I). Metanoto com cerdas simples, mais longas nas áreas dorsolaterais; disco basal do propódeo, glabro. Margem posterior dos esternos metassomáticos III, IV e V com fileira de cerdas de ápices finos, curvados em gancho, formando estruturas semelhante a pente (fig. 12). No esterno II, cerdas mais irregulares. Tergos I e II glabros, apenas microcerdas esparsas na margem apical do II; tergos III-V com cerdas esparsas nos lados e na margem apical (cerca de 0,08); VI com cerdas eretas, simples e longas (cerca de 0,12 ), esparsas, intercaladas à pilosidade plumosa decumbente densa.

Integumento liso e brilhante, apenas com pontuação pilígera fina.

Mensurações (tab. I). Cabeça 1,25 vezes mais larga que longa, mais larga que o tórax e que o tergo II. Olhos 2,4 vezes mais longos que largos, convergentes inferiormente; interorbital superior 1,4 vezes maior que o comprimento do olho. Área malar 1,45 vezes o 


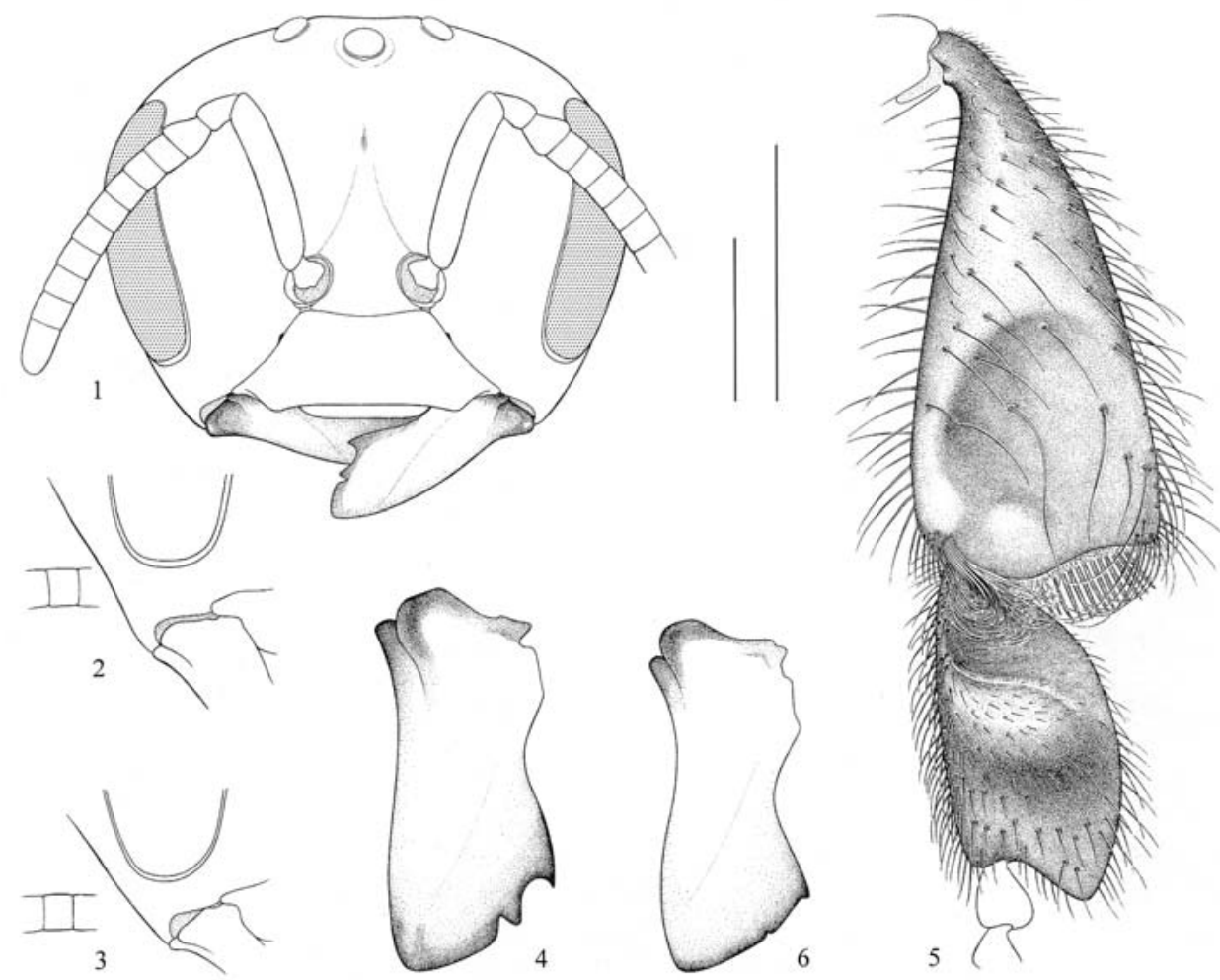

Figs. 1-6. Schwarzula coccidophila sp. nov., operária: 1, cabeça; 2, detalhe da área malar e $3^{\circ}$ flagelômero; 4, mandíbula; 5, perna posterior. Schwarzula timida (Silvestri), operária: 3 , detalhe da área malar e $3^{\circ}$ flagelômero. Scaura latitarsis (Friese), operária: 6, mandíbula. Escalas: 0,5 mm; barra menor figs. 1-3, barra maior figs. 4-6.

diâmetro do $3^{\circ}$ flagelômero (fig. 2). Clípeo muito curto e largo (fig. 1), em forma de trapézio de lados quase retos, 2,6 vezes mais largo que longo, comprimento pouco mais que $1 / 4$ da distância clipeocelar. Distância interalveolar 1,2 vezes maior que o diâmetro do alvéolo, e este um pouco menor que metade da distância alveolorbital. Sulco frontal rebaixado no meio da fronte. Distância entre os ocelos laterais 2,5 vezes o diâmetro do ocelo médio e apenas um pouco menor que a ocelorbital. Vértice arredondado, não elevado. Contorno pré-occipital arredondado. Comprimento do escapo 5,6 vezes seu diâmetro e 4/5 da distância entre o alvéolo e o ocelo lateral. Mandíbula robusta, pouco mais curta que a largura máxima do clípeo; dois dentes agudos ocupando o terço interno da borda laminar apical, separados por amplo semicírculo (figs. 1, 4). Escutelo semicircular, pouco mais que 2 vezes mais largo que longo; sutura escuto-escutelar bastante rebaixada. Asa anterior 2,4 vezes mais longa que larga; pterostigma 4,7 vezes sua largura; célula marginal alongada, cerca de 4 vezes mais longa que larga, fechada no ápice; ângulo entre as nervuras $\mathrm{M}$ e $\mathrm{M}+\mathrm{Rs}$ aberto, cerca de $130^{\circ} ; 1^{\mathrm{a}}$ abscissa de $\mathrm{M}, 0,74$ vezes mais curta que a 
$1^{\text {a }}$ abscissa de $\mathrm{Cu}$; apenas a $1^{\text {a }}$ célula submarginal muito fracamente delimitada, a $2^{\text {a }}$ inconspícua. Hâmulos, 5. Tíbia posterior subtriangular, 2,4 vezes mais longa que larga, margem posterior em arco suave; borda distal sinuosa, e canto posterior praticamente formando um ângulo reto, levemente arredondado; corbícula ocupando aproximadamente a metade apical, fracamente côncava; parapenicilos anterior e posterior muito desenvolvidos (fig. 5). Basitarso posterior largo, pouco menos que 4/6 do comprimento, fortemente intumescido na metade apical; borda distal em ângulo de $120^{\circ}$ em relação à borda anterior e canto póstero-distal arredondado (fig. 5).

Macho (figs. 7-11). Dimensões (tab. I). Integumento preto; amarelo-âmbar as seguintes áreas (exemplar jovem): clípeo por inteiro, área malar, labro, mandíbulas, extremidades distal e proximal do escapo da antena, pronoto, parte ventral e superior dos mesepisternos, parte das tégulas, escutelo, metanoto e propódeo, extremidades distal e proximal da tíbia, basitarso e tarsômeros de todas as pernas, esternos I-III e tergos I e II. Asas como na operária. Em outros machos do mesmo ninho, mais pigmentados, amareloâmbar escuro apenas o labro, uma estreita faixa no ápice do clípeo, basitarso, tarsômeros e extremidades distal e proximal das tíbias de todas as pernas; metanoto e escutelo descoloridos, mesmo em exemplares mais pigmentados.

Pilosidade predominantemente amarelo-pálida; mais esbranquiçada no mesoscuto e esternos metassomáticos, e pilosidade plumosa, decumbente, da face. Nas asas, ferrugíneo-fusca. Pilosidade plumosa decumbente da face e clípeo, densa, como na operária, porém bem mais rala nos mesepisternos e escutelo e praticamente ausente no último tergo. Comprimento das cerdas (tab. I). Disco basal do propódeo glabro. Tergos I e II praticamente glabros; os demais com algumas cerdas eretas esparsas; esternos III-V, com tufos de cerdas simples, longas, algumas encurvadas na ponta; esterno V (fig. 7).

Integumento como na operária, apenas na fronte, finamente rugoso, vermiculado (melhor visualizado nos parátipos do ninho 741c).

Mensurações (tab. I). Cabeça 1,3 vezes mais larga que longa, mais larga que o tórax e o abdômen. Olhos quase 2 vezes mais longos que largos, convergentes inferiormente; distância interorbital superior igual ao comprimento do olho. Área malar muito curta, menos que metade do diâmetro do $3^{\circ}$ flagelômero. Clípeo em forma de trapézio de lados quase retos, 1,9 vezes mais largo que longo, seu comprimento um pouco menor que $1 / 3$ da distância clipeocelar. Distância interalveolar igual ao diâmetro do alvéolo, e este pouco menor que a distância alveolorbital. Fronte com linha média longitudinal saliente; sulco frontal, abaixo da linha média, bem marcado. Distância entre os ocelos laterais 1,9 vezes o diâmetro do ocelo médio e 1,5 vezes maior que a ocelorbital. Vértice arredondado, não elevado; contorno pré-occipital arredondado. Comprimento do escapo 3,4 vezes seu diâmetro, e 5/7 da distância entre o alvéolo e o ocelo lateral. Escutelo quase semicircular, um pouco mais que 2 vezes mais largo que longo; sutura escuto-escutelar bastante rebaixada. Asa anterior 2,7 vezes mais longa que larga; pterostigma 4,5 vezes mais longo que largo; célula marginal 4,6 vezes mais longa que larga, aberta no ápice; ângulo entre $\mathrm{M}$ e $\mathrm{M}+\mathrm{Rs}$, aberto, $135^{\circ} ; 1^{\mathrm{a}}$ abscissa de $\mathrm{M}, 0,7$ vezes mais curta que a $1^{\mathrm{a}}$ abscissa de $\mathrm{Cu}$; $1^{\mathrm{a}}$ célula submarginal muito fracamente delimitada, a $2^{\mathrm{a}}$ inconspícua. Hâmulos, 5. Tíbia posterior subtriangular, com as margens anterior e posterior em arco suave, 2,7 vezes mais longa que larga, intumescida. Basitarso posterior 1,7 vezes mais longo que largo, fortemente intumescido em toda a extensão. Genitália e esternos (figs. 7-11). 
Tabela I. Medidas dos exemplares de Schwarzula (em milímetros).

\begin{tabular}{|c|c|c|c|c|c|c|c|c|}
\hline & \multicolumn{5}{|c|}{ Schwarzula coccidophila sp. nov. } & \multirow[b]{2}{*}{$\mathrm{n}$} & \multicolumn{2}{|c|}{ Schwarzula timida } \\
\hline & $\begin{array}{l}\text { Holótipo } \\
\text { operária }\end{array}$ & $\begin{array}{l}\text { operária } \\
\text { média }\end{array}$ & $\mathrm{n}$ & $\begin{array}{l}\text { alótipo } \\
\text { macho }\end{array}$ & $\begin{array}{l}\text { machos } \\
\text { média }\end{array}$ & & $\begin{array}{l}\text { operárias } \\
\text { média }\end{array}$ & $\mathrm{n}$ \\
\hline Comprimento total aproximado & 3,52 & $3,74 \pm 0,20$ & 10 & 3,51 & $3,82 \pm 0,21$ & 4 & $3,55 \pm 0,28$ & 6 \\
\hline Largura máxima cabeça & 1,60 & $1,61 \pm 0,05$ & 10 & 1,63 & $1,64 \pm 0,02$ & 4 & $1,56 \pm 0,07$ & 6 \\
\hline Comprimento cabeça & 1,28 & $1,26 \pm 0,05$ & 10 & 1,26 & $1,26 \pm 0,01$ & 4 & $1,18 \pm 0,05$ & 6 \\
\hline Comprimento olho & 0,86 & $0,86 \pm 0,03$ & 10 & 1,02 & $1,03 \pm 0,01$ & 4 & $0,90 \pm 0,03$ & 6 \\
\hline Largura olho & 0,36 & $0,36 \pm 0,04$ & 10 & 0,52 & $0,53 \pm 0,02$ & 4 & $0,40 \pm 0,01$ & 6 \\
\hline Distância interorbital superior & 1,20 & $1,19 \pm 0,04$ & 10 & 1,02 & $1,01 \pm 0,02$ & 4 & $1,05 \pm 0,05$ & 6 \\
\hline Distância interorbital máxima & 1,24 & $1,25 \pm 0,04$ & 10 & 1,07 & $1,06 \pm 0,02$ & 4 & $1,15 \pm 0,05$ & 6 \\
\hline Distância interorbital inferior & 1,08 & $1,07 \pm 0,03$ & 10 & 0,79 & $0,78 \pm 0,02$ & 4 & $0,95 \pm 0,05$ & 5 \\
\hline Diâmetro ocelo & 0,13 & $0,13 \pm 0,01$ & 10 & 0,18 & $0,18 \pm 0,01$ & 4 & $0,13 \pm 0,01$ & 6 \\
\hline Distância interocelar & 0,33 & $0,33 \pm 0,01$ & 10 & 0,34 & $0,34 \pm 0,01$ & 4 & $0,35 \pm 0,02$ & 6 \\
\hline Distância ocelorbital & 0,35 & $0,36 \pm 0,01$ & 10 & 0,23 & $0,22 \pm 0,01$ & 4 & $0,29 \pm 0,02$ & 6 \\
\hline Distância interalveolar & 0,19 & $0,19 \pm 0,01$ & 10 & 0,18 & $0,18 \pm 0,01$ & 4 & $0,17 \pm 0,01$ & 6 \\
\hline Distância alveolorbital & 0,33 & $0,31 \pm 0,02$ & 10 & 0,20 & $0,19 \pm 0,01$ & 4 & $0,27 \pm 0,02$ & 6 \\
\hline Distância alvéolo-ocelo lateral & 0,70 & $0,71 \pm 0,03$ & 10 & 0,62 & $0,62 \pm 0,00$ & 4 & $0,66 \pm 0,04$ & 6 \\
\hline Diâmetro alvéolo & 0,16 & $0,16 \pm 0,01$ & 10 & 0,18 & $0,19 \pm 0,01$ & 4 & $0,16 \pm 0,01$ & 6 \\
\hline Comprimento clípeo & 0,31 & $0,39 \pm 0,01$ & 10 & 0,36 & $0,34 \pm 0,02$ & 4 & $0,27 \pm 0,02$ & 6 \\
\hline Largura máxima clípeo & 0,80 & $0,78 \pm 0,04$ & 09 & 0,70 & $0,68 \pm 0,02$ & 4 & $0,75 \pm 0,04$ & 6 \\
\hline Distância clípeo-ocelar & 1,12 & $1,11 \pm 0,03$ & 10 & 1,12 & $1,08 \pm 0,03$ & 4 & $1,03 \pm 0,07$ & 6 \\
\hline Comprimento área malar & 0,16 & $0,16 \pm 0,01$ & 10 & 0,06 & $0,06 \pm 0,00$ & 4 & $0,09 \pm 0,02$ & 6 \\
\hline Comprimento escapo & 0,56 & $0,57 \pm 0,02$ & 10 & 0,44 & $0,45 \pm 0,01$ & 4 & $0,54 \pm 0,03$ & 6 \\
\hline Diâmetro escapo & 0,10 & $0,10 \pm 0,00$ & 10 & 0,13 & $0,13 \pm 0,00$ & 4 & $0,10 \pm 0,01$ & 6 \\
\hline Comprimento pedicelo + flagelo & 1,14 & $1,13 \pm 0,04$ & 10 & 1,86 & $1,85 \pm 0,01$ & 4 & $1,14 \pm 0,06$ & 6 \\
\hline Comprimento flagelômero 1 & 0,08 & $0,10 \pm 0,01$ & 10 & 0,06 & $0,06 \pm 0,00$ & 4 & $0,08 \pm 0,01$ & 6 \\
\hline Comprimento flagelômero 2 & 0,08 & $0,08 \pm 0,00$ & 10 & 0,18 & $0,18 \pm 0,00$ & 4 & $0,09 \pm 0,01$ & 6 \\
\hline Comprimento flagelômero 3 & 0,09 & $0,08 \pm 0,01$ & 10 & 0,17 & $0,16 \pm 0,01$ & 4 & $0,09 \pm 0,01$ & 6 \\
\hline Comprimento último flagelômero & 0,18 & $0,19 \pm 0,01$ & 10 & 0,25 & $0,25 \pm 0,01$ & 4 & $0,20 \pm 0,02$ & 6 \\
\hline Diâmetro flagelômero 3 & 0,11 & $0,11 \pm 0,01$ & 10 & 0,14 & $0,14 \pm 0,01$ & 4 & $0,10 \pm 0,01$ & 6 \\
\hline Comprimento mandíbula & 0,70 & $0,69 \pm 0,04$ & 10 & 0,40 & $0,40 \pm 0,02$ & 4 & $0,64 \pm 0,03$ & 6 \\
\hline Comprimento asa anterior & 3,06 & $3,27 \pm 0,36$ & 10 & 3,52 & $3,56 \pm 0,03$ & 3 & $3,01 \pm 0,22$ & 6 \\
\hline Compr. asa anterior + tégula & 3,54 & $3,70 \pm 0,39$ & 10 & 3,87 & $3,92 \pm 0,11$ & 3 & $3,41 \pm 0,25$ & 6 \\
\hline Largura asa anterior & 1,29 & $1,35 \pm 0,14$ & 09 & $\sim 1,32$ & $1,37 \pm 0,05$ & 3 & $1,35 \pm 0,08$ & 4 \\
\hline Comprimernto pterostigma & 0,56 & $0,55 \pm 0,03$ & 10 & 0,72 & $0,73 \pm 0,02$ & 4 & $0,56 \pm 0,03$ & 6 \\
\hline Largura pterostigma & 0,12 & $0,13 \pm 0,01$ & 10 & 0,16 & $0,16 \pm 0,00$ & 3 & $0,13 \pm 0,01$ & 6 \\
\hline Comprimento célula marginal & 0,98 & $0,97 \pm 0,05$ & 10 & 1,20 & $1,19 \pm 0,01$ & 3 & $0,96 \pm 0,07$ & 6 \\
\hline Largura célula marginal & 0,25 & $0,26 \pm 0,01$ & 10 & 0,26 & $0,26 \pm 0,00$ & 2 & $0,27 \pm 0,01$ & 6 \\
\hline Hâmulos & 5 & $5 \pm 0,00$ & 10 & 5 & $5 \pm 0,00$ & 3 & $5 \pm 0,00$ & 6 \\
\hline Largura mesoscuto & 1,08 & $1,06 \pm 0,05$ & 10 & 1,08 & $1,13 \pm 0,04$ & 4 & $0,97 \pm 0,07$ & 6 \\
\hline Comprimento mesoscuto & 0,86 & $0,86 \pm 0,03$ & 10 & 1,12 & $1,12 \pm 0,03$ & 4 & $0,78 \pm 0,03$ & 6 \\
\hline Largura escutelo & 0,64 & $0,64 \pm 0,03$ & 10 & 0,71 & $0,71 \pm 0,01$ & 4 & $0,57 \pm 0,05$ & 6 \\
\hline Comprimento escutelo & 0,30 & $0,31 \pm 0,02$ & 10 & 0,34 & $0,34 \pm 0,01$ & 4 & $0,26 \pm 0,02$ & 6 \\
\hline Comprimento tíbia posterior & 1,18 & $1,18 \pm 0,05$ & 10 & 1,18 & $1,20 \pm 0,03$ & 4 & $1,10 \pm 0,06$ & 6 \\
\hline Largura tíbia posterior & 0,49 & $0,50 \pm 0,01$ & 10 & 0,44 & $0,45 \pm 0,01$ & 4 & $0,47 \pm 0,04$ & 6 \\
\hline Comprimento basitarso posterior & 0,56 & $0,59 \pm 0,04$ & 10 & 0,58 & $0,58 \pm 0,01$ & 4 & $0,58 \pm 0,02$ & 6 \\
\hline Largura basitarso posterior & 0,36 & $0,38 \pm 0,02$ & 10 & 0,34 & $0,34 \pm 0,01$ & 4 & $0,38 \pm 0,03$ & 6 \\
\hline Largura tergo II & $\sim 1,56$ & $1,55 \pm 0,09$ & 02 & $?$ & $1,62 \pm 0,06$ & 2 & $1,24 \pm 0,10$ & 6 \\
\hline Comprimento cerdas do escapo & 0,07 & $0,06 \pm 0,01$ & 10 & 0,06 & $0,06 \pm 0,01$ & 4 & $0,05 \pm 0,01$ & 6 \\
\hline Comprimento cerdas do clípeo & 0,06 & $0,06 \pm 0,01$ & 10 & 0,11 & $0,11 \pm 0,01$ & 3 & $0,10 \pm 0,02$ & 6 \\
\hline Comprimento cerdas da fronte & 0,08 & $0,07 \pm 0,01$ & 10 & 0,09 & $0,10 \pm 0,02$ & 4 & $0,11 \pm 0,02$ & 6 \\
\hline Comprimento cerdas do vértice & 0,16 & $0,16 \pm 0,02$ & 10 & 0,22 & $0,22 \pm 0,01$ & 4 & $0,16 \pm 0,02$ & 6 \\
\hline Comprim. cerdas do mesepisterno & 0,11 & $0,11 \pm 0,02$ & 10 & 0,12 & $0,13 \pm 0,01$ & 4 & $0,13 \pm 0,02$ & 6 \\
\hline Comprim. cerdas do mesoscuto & 0,08 & $0,08 \pm 0,01$ & 10 & 0,10 & $0,11 \pm 0,01$ & 4 & $0,11 \pm 0,01$ & 6 \\
\hline Comprimento cerdas do escutelo & 0,24 & $0,23 \pm 0,01$ & 10 & 0,28 & $0,27 \pm 0,02$ & 4 & $0,24 \pm 0,02$ & 6 \\
\hline
\end{tabular}


Variação. Em alguns parátipos do mesmo ninho do holótipo (878c), o clípeo é todo âmbar, em outros, todo preto. Exemplares de Aruti (operárias), região do médio rio Negro, apresentam, além das manchas no clípeo, uma mancha parocular amarelo-âmbar ou amarelo-marfim a cada lado, acompanhando o quarto inferior do olho, em forma de $\mathrm{L}$ ou triângulo-retângulo, chegando quase a encostar na sutura epistomal. Operárias de $S$. coccidophila apresentam grande variação no tamanho, e podem ser confundidas com $S$. timida, entretanto, como indicado na diagnose, podem ser reconhecidas pelo comprimento da área malar (figs. 2,3).

Tipos. Holótipo operária e alótipo macho, de Tapurucuara-Mirim, rio Negro, Amazonas, Brasil, 00²3'28'S, 66'26'07'W, 15.II.2001 Camargo col. (RPSP, ambos com o número de série-ninho, 878c), e seguintes parátipos: 242 operárias e 3 machos, em alfinetes, mais exemplares em fixador, todos do mesmo ninho (878c); 58 operárias, rainha, mais exemplares em fixador (RPSP, ninho 741c), de Tapurucuara-Mirim, rio Negro, Amazonas, Brasil, 00²5’S, 66²4’W, 01-04.VII.1999, Camargo, Pedro \& Mazucato col.

Material examinado. BRASIL, Amazonas: Camanaus, rio Negro, 66 $6^{\circ} 56^{\prime} \mathrm{W}, 00^{\circ} 08^{\prime} \mathrm{S}, 2$ operárias, 28,29.VI.1999, Camargo, Pedro \& Mazucato col. (RPSP 993963, 994157); Foz do rio Curicuriari, rio Negro, SA-19, 66 $49^{\prime} \mathrm{W}, 00^{\circ} 13^{\prime}$ 'S, 3 operárias, 15-21.VII.1980, Camargo \& Mazucato col. (RPSP); São Jorge, rio Curicuriari, 66 $6^{\circ} 50^{\prime} \mathrm{W}, 00^{\circ} 13^{\prime} \mathrm{S}$, 5 operárias, 26,27.VI.1999, Camargo, Pedro \& Mazucato col. (RPSP 993435-993437, 993473, 993474); Plano, rio Negro, 6559'W, 00¹8'S, operária, 07-09.VII.1999, Camargo, Pedro \& Mazucato col. (RPSP 995410); Aruti, rio Negro, SA-19, $66^{\circ} 02^{\prime} \mathrm{W}, 00^{\circ} 19^{\prime} \mathrm{S}, 9$ operárias, 22,23.VII.1980, Camargo \& Mazucato col. (RPSP);

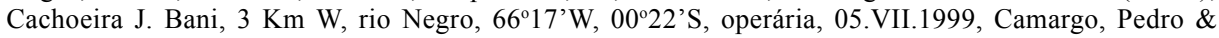
Mazucato col. (RPSP 995241); Foz do rio Daraã, rio Negro, SA-20, 644ㄱ' W, $00^{\circ} 25^{\prime}$ 'S, 59 operárias mais material em fixador, 02-04.VIII.1980, Camargo \& Mazucato col. (RPSP, ninho 261c); Morro 6 Lagos (Santa Isabel do Rio Negro), 7 operárias, 28,29.III.1990, alto do morro, L. S. Aquino col. (INPA); (São Gabriel da Cachoeira), operária, 28.IX-06.X.1990, 800 m, malaise, J. A. Rafael \& J. Vidal col. (INPA); (Santa Isabel do Rio Negro), $65^{\circ} 01^{\prime} \mathrm{W}, 00^{\circ} 25^{\prime} \mathrm{S}, 2$ operárias, 11,12.VII.1999, Camargo, Pedro \& Mazucato col. (RPSP 995927, 995929); Tapurucuara-Mirim, rio Negro, 66²4'W, 00²5'S, 8 operárias, 01-04.VII.1999, Camargo, Pedro \& Mazucato col. (RPSP 994797, 994812, 995083, 995185-995189); Samaúma, rio Daraã, 64²4 'W, 00²6'S, operária, 17-20.VII.1999, Camargo, Pedro \& Mazucato col. (RPSP 996870); Tabocal, rio Uneiuxi, $65^{\circ} 06^{\prime} \mathrm{W}, 00^{\circ} 35^{\prime} \mathrm{S}$, operária, 13-15.VII.1999, Camargo, Pedro \& Mazucato col. (RPSP 996070); Maraã, 65³5'W, 01⒌' 'S, operária, 15-19.VIII.1993, Camargo, Pedro \& Mazucato col. (RPSP 935396); Itacoatiara, AM 010, Km 215, Faz. Aruanã, operária, 17.VIII.1990, baunilha, F. J. A. Peralta col. (INPA); Tefé, SA-20, 65-3g.III, operária, 27-30.I.1977, Camargo \& Mazucato col. (RPSP); Lago Janauacá, operária,

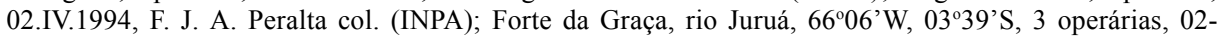
06.VIII.1993, Camargo, Pedro \& Mazucato col. (RPSP 933883, 933884, 933888); Carauari, rio Juruá, 6654'W, 0453'S, operária, 20-24.VII.1993, Camargo, Pedro \& Mazucato col. (RPSP 933015); Camaruã, $15 \mathrm{Km}$ a jusante, Purus, SB-20, $64^{\circ} 25^{\prime} \mathrm{W}, 05^{\circ} 40^{\prime} \mathrm{S}$, operária, 31.I-01.II.1986, Camargo \& Mazucato col. (RPSP 861332); Rio Ipixuna, Purus, SB-20, 632ㅇ' W, 06 $00^{\circ}$ 'S, operária, 20-23.I.1986,

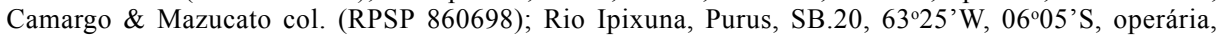
16-19.I.1986, Camargo \& Mazucato col. (RPSP 860437); Poço Pion-Petrobrás, Tefé, 300 Km SE, operária, 1988, W. E. Kerr col. (RPSP 881707); Acre: Parque Nacional Serra do Divisor (Trilha do Anil), Sítio 6, 07²6’27”S, 73³9’28”W, 2 operárias, 08,09.XI.1996 (RPSP 971589, 971590); (Morro Queimado), Sítio 1, 07²6’36”S, 7340’28”W, operária, 10.XI.1996 (RPSP 970842); (Rio das Minas), Sítio 6, 08³3’30”S, 7253’30”W, 9 operárias, 19.III.1997 (RPSP 972515-972517, 972529, 972530, 972532, 972534-972536); (Rio Juruá), Sítio 10, 0852’31”S, 7246’55”W, 19 operárias, 24.III.1997 (RPSP 973112-973130), todos coletados por E. F. Morato; Rio Branco, BR 317 FUNTAC, operária, 21.V.1990, L. A. O. Campos col. (RPSP); Rondônia: Porto Velho, 2 operárias, 12-22.X.1966, Camargo col. (RPSP); Rio Candeias, reg. Campo Novo, operária, 06.VIII.1985, V. Py Daniel \& L. Aquino col. (INPA); Ouro Preto, 17.IX.1996, Brown, Boina \& Vieira col. (RPSP 2702); Nova União, $10^{\circ} 49,958^{\prime} \mathrm{S}, 6^{\circ} 29,930^{\prime} \mathrm{W}$, operária, 19.XII.1996, Brown, 

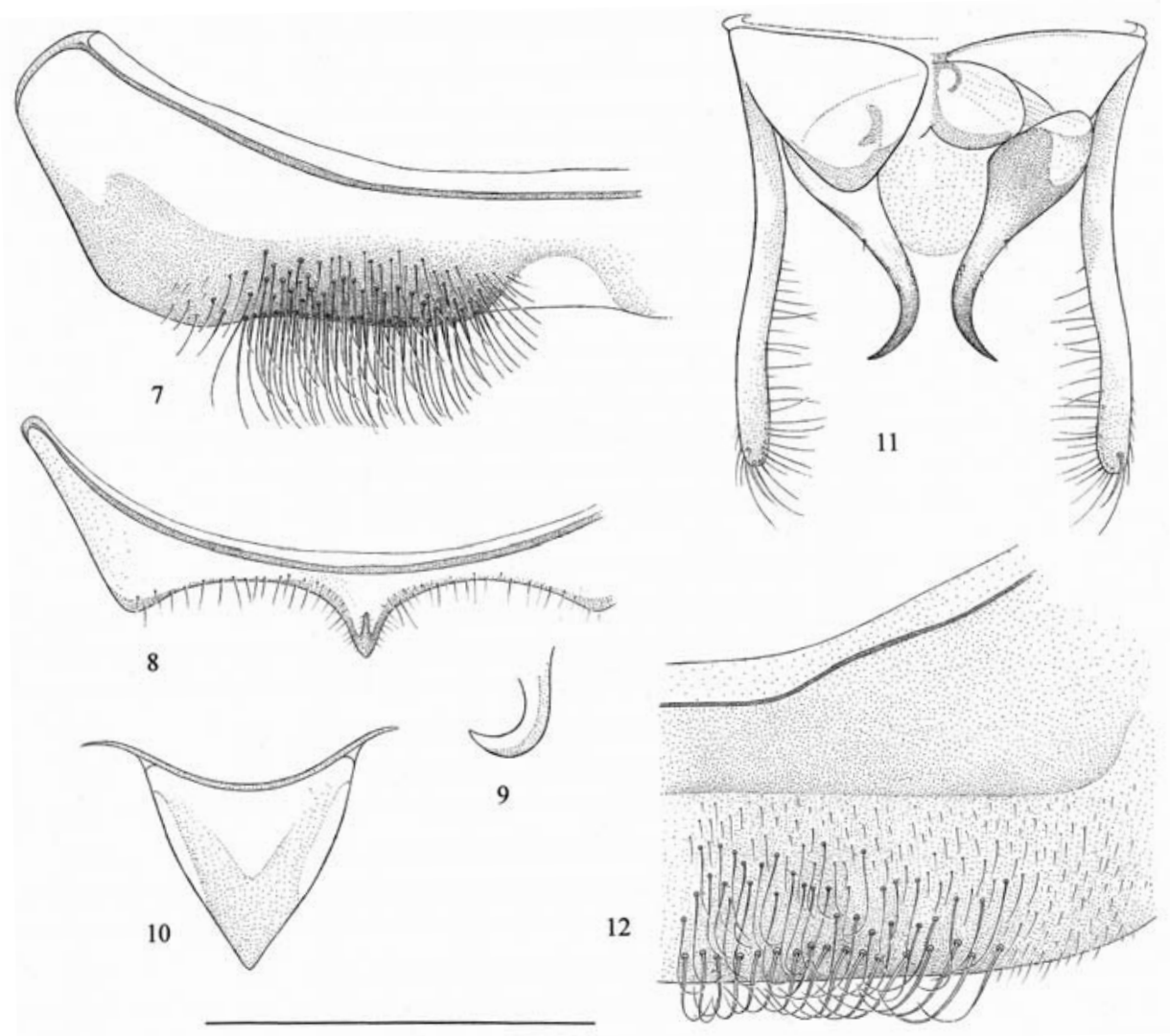

Figs. 7-12. Schwarzula coccidophila sp. nov., 7-11, macho: 7, 8, esternos metassomáticos V e VI; 9, perfil da projeção mediana do esterno VI; 10 , esterno metassomático VII; 11, genitália, vista ventral e dorsal. 12, operária, detalhe das cerdas marginais do esterno metassomático IV. Escala, 0,5 mm.

Boina, \& Vieira col. (RPSP 4403); Mirante da Serra, 10 $0^{\circ} 56,284^{\prime} \mathrm{S}, 6^{\circ} 42,425^{\prime} \mathrm{W}, 4$ operárias,

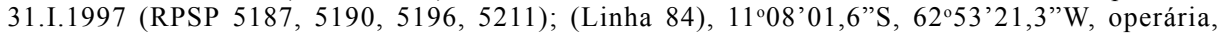

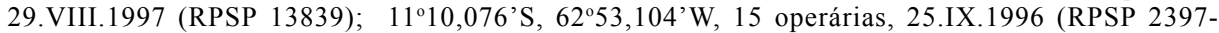
2399, 2409, 2414-2418, 2420-2425), todos coletados por Brown, Boina \& Vieira. PERU, Huanuco: Pachitea, operária, sem data, sem dados de coletor (RPSP).

Distribuição geográfica. Região oeste do Amazonas, Acre, Rondônia, (Brasil)e Peru (fig. 13).

Nidificação. Em galerias escavadas por larvas de mariposa (Cossidae), dentro do tronco e ramos Campsiandra angustifolia Spruce ex Benth., 1870, Caesalpiniaceae, em associação mutualística com cochonilhas, Cryptostigma sp., Coccidae (CAMARGO \& Pedro, 2002). Dos mais de 50 ninhos observados, só um (RPSP, ninho 261c, foz do rio Daraã, AM) não se encontrava em galerias escavadas por larva de Cossidae. Geralmente constituem grandes agregações de ninhos nos ramos de uma mesma árvore. Em um espécimen de $C$. angustifolia havia mais de 30 ninhos. Esta é uma das plantas mais 
conspícuas dos igapós e margens do rio Negro, onde é conhecida pelo nome de cumandá. Detalhes do ninho são apresentados em CAMARGo \& PEDro (2002).

Discussão. Schwarzula pode ser reconhecido pelas seguintes autapomorfias: clípeo curto e muito alargado (cerca de 2,6 vezes mais largo que longo, fig. 1); mandíbulas muito fortes e robustas, intumescidas, comparativamente com Scaura Schwarz, 1938, com dois dentes no 1/3-1/2 interno da borda apical, separados por largo recorte semicircular (figs. $1,4,6)$; área malar igual ou um pouco mais longa que o diâmetro do $3^{\circ}$ flagelômero; basitarsos posteriores levemente mais estreitos que a tíbia, intumescidos na metade apical (fig. 5) e com a superfície interna levemente côncava (outras combinações de caracteres em Moure , 1946, 1951) e pelos hábitos coccidófilos. Compartilha com Scaura, principalmente o caráter fileira de cerdas eretas com pontas curvadas em direção anterior, dispostas ao longo das margens posteriores dos esternos III a $\mathrm{V}$ e, às vezes, no II (MichENER, 1990, 2000), formando estruturas semelhantes a pentes, além da glossa mais curta que o premento (Michener \& Roubik, 1993), e presença de cerdas com ápice fortemente encurvado, acompanhando a borda anterior da superfície interna dos basitarsos posteriores. Os basitarsos posteriores expandidos e intumescidos em Schwarzula e fortemente expandidos e intumescidos em Scaura, também, supostamente, são estados diferentes de um mesmo caráter. A forma do esterno VI dos machos das espécies de Scaura, S. tenuis (Ducke, 1916), S. latitarsis (Friese, 1900) e S. longula (Lepeletier, 1836), é praticamente idêntica àquela de Schwarzula coccidophila. A congruência entre esses atributos morfológicos é indício de que estes surgiram, combinados, uma única vez na história dos Meliponini, sinapomorfias legítimas, o que permite hipotetizar que Scaura e Schwarzula são clados irmãos.

Os basitarsos posteriores expandidos, com cerdas especializadas na parte anterior da superfície interna, são adaptações, conforme foi observado em Scaura latitarsis (Laroca \& Lauer, 1973; RoubiK \& Moreno, 2000), e S. longula (Michener et al., 1978), para raspar pólen caído sobre a superfície de pétalas e folhas pela atividade de outras abelhas. LAROCA \& LAUER (1973) observaram S. latitarsis raspando, com os basitarsos, inflorescências cilíndricas de Piper L., e DuCKe $(1901,1902)$ registrou Melipona crassipes (Fabricius, 1793) [= Scaura longula] em Piperaceae. Para as espécies de Schwarzula não há observações; todavia, por inferência, pode-se supor que o comportamento de coleta de pólen seja o mesmo. Em Schwarzula coccidophila, estas estruturas atendem, ainda, uma segunda demanda evolutiva: os basitarsos são utilizados para raspar cera da superfície dorsal do corpo de coccídeos que vivem no interior do ninho (CAMARGO \& Pedro, 2002). Quanto às fileiras de cerdas nos esternos metassomáticos, também é possível que estejam associadas ao comportamento de raspar pólen. O comportamento de Scaura latitarsis de percorrer para cima e para baixo inflorescências em forma de espiga de Piper, descrito por LAROCA \& LAUER (1973), permite supor que o pólen entre em contato com esses pentes e aí fique aderido.

\section{Schwarzula timida (Silvestri, 1902)}

(Figs. 3, 14)

Trigona timida Silvestri, 1902:163-164, pl. II, fig. 30, pl. III figs. 47, 48; Ihering, 1930:712; SChwARZ, 1932:246; 1948:23, 72; DarChen \& Louis, 1961:30; Wille, 1979:267.

Trigona (Scaura) timida; Wille \& Michener, 1973:12, 21, 44, 55, 67; Wille, 1979:267; 1983:50.

Iheringia, Sér. Zool., Porto Alegre, 92 (3):101-112, 30 de setembro 2002 
Plebeia (Scaura) timida; Michener, 1990:87, 112, 114; 2000:797, 798; Michener \& RoubiK, 1993:255. Melipona timida; DucKe, 1916:13, 25, 30, 48, 88; 1925: 340, 342, 348, 365.

Melipona (Trigona) timida; IHERING, 1968:305.

Scaura timida; NogueIRA-Neto, 1997:249.

Scaura (Schwarzula) timida; LeNKo \& PAPAVERo, 1996:271.

Schwarzula timida; Moure, 1946:439-440; 1950a:72, 73; 1950b:241; 1951:52; Nogueira-Neto, 1970:34, 39, 51, 54; 1997:48, 52; Camargo, 1988:363; Camargo \& Moure, 1988:293, 310, 311; Camargo, 1994:50, 53; Oliveira \& Morato, 1994:291; Lenko \& Papavero, 1996:267.

\section{Macho. Desconhecido.}

Variação. Como observado por CAMARGO (1988), há uma variação grande no tamanho dos exemplares examinados de Schwarzula timida (tab. I) e é possível que inclua mais de uma espécie.

Tipos. Redescrição e designação do lectótipo feita por CAMARGO \& MOURE (1988).

Material examinado. BRASIL, Pará: Lago Água Fria, rio Trombetas, SA-21, 56 $51 \mathrm{~W}, 01^{\circ} 25^{\prime}$ S, operária, 13-15.II.1979, Camargo col. (RPSP); Santarém, operária (CMNH 2966); Amazonas: São Jorge, rio Curicuriari, 66 ${ }^{\circ} 50^{\prime} \mathrm{W}, 00^{\circ} 13^{\prime} \mathrm{S}, 2$ operárias, 26,27.VI.1999, Camargo, Pedro \& Mazucato col. (RPSP 993438, 993439); Cachoeira J. Bani, $3 \mathrm{Km} \mathrm{W}$, rio Negro, 66²17’W, 00²2'S, operária, 05.VII.1999, Camargo, Pedro \& Mazucato col. (RPSP 995240); Tapurucuara-Mirim, rio Negro, $66^{\circ} 24^{\prime} \mathrm{W}, 00^{\circ} 25^{\prime}$ S, 2 operárias, 01-04.VII.1999, Camargo, Pedro \& Mazucato col. (RPSP 994759, 994768); Nazaré, rio Negro, 6504'W, 00³1'S, operária, 15, 16.VII.1999, Camargo, Pedro \& Mazucato col. (RPSP 996677); BR 174, ZF6, Km 9, 3 operárias, 06.II.1986, M. V. B. Garcia col. (INPA, ninho 012); Tefé, SA-20, 65-3g.III, 2 operárias, 27-30.I.1977, Camargo \& Mazucato col. (RPSP); B.A.B.A. [sic Bê-á-bá], Purus, SB-20, 625' 'W, 0452'S, operária, 12,13.II.1986, Camargo \& Mazucato col. (RPSP 862113); Acre: Parque Nacional Serra do Divisor (Rio Azul, Sítio 8, 07³3'24'S, 73¹6'36”W), operária, 24.XI.1996 (RPSP 971898); (Rio das Minas, Sítio 6, 08³3’30”S, 7253’30”W), 48 operárias, 19.III.1997 (RPSP 972478-972490, 972492-972503, 972505-972514, 972518-972528, 972531, 972533), todos coletados por E. F. Morato; Sena Madureira, rio Caeté, 68 40 4, $8^{\prime}$ 'W, 0903'14,4”S, operária, 2.IV.1994, E. F. Morato col. (RPSP); Rondônia: Cujubim, Linha 46 a Machadinho, 09²4,606'S, 62³3,479'W, operária, 25.III.1997, (RPSP 7105); Nova Mamoré, $10^{\circ} 24,410 \mathrm{~S}, 65^{\circ} 00,406^{\prime} \mathrm{W}$, operária, 13.IX.1996 (RPSP 63); Guajará-Mirim, $10^{\circ} 45,516^{\prime} \mathrm{S}$, $64^{\circ} 42,761^{\prime} \mathrm{W}, 4$ operárias, 09.X.1996 (RPSP 1907, 1909, 1911, 1923); 1049,871'S, 64⒌55,984'W, 10 operárias, 07.X.1996 (RPSP 1639-1642, 1646, 1648); 1050,408'S, 645ㄱ,756'W, 4 operárias, 07.X.1996 (RPSP 1610,1624, 1626, 1627, 1628); 1051,113'S, 645ㅇ,406'W, 8 operárias, 06.X.1996, (RPSP 1532, 1536, 1537, 1541-1545); Nova União, $10^{\circ} 51,788^{\prime} \mathrm{S}, 62^{\circ} 23,348^{\prime} \mathrm{W}, 2$ operárias, 08.III.1997 (RPSP 6202, 6204); Mirante da Serra, 1056,284'S, 62²42,425'W, operária, 31.I.1997 (RPSP 5168); Costa Marques, $12^{\circ} 17,653^{\prime} \mathrm{S}, 6^{\circ} 01,804^{\prime} \mathrm{W}, 3$ operárias, 21.XI.1996 (RPSP 3552, 3574); Pimenteiras, $1^{\circ} 35,642^{\prime}$ 'S, $61^{\circ} 27,764^{\prime} \mathrm{W}, 7$ operárias, 20.II.1997 (RPSP 5698, 5700, 5702-5706); 12 $2^{\circ} 38,100^{\prime} \mathrm{S}, 61^{\circ} 26,147^{\prime} \mathrm{W}$, operária, 20.II.1997 (RPSP 5626), todos os espécimens de Rondônia coletados por Brown, Boina \& Vieira; Mato Grosso: Chapada, 5 operárias, III (ano ?) (CMNH 2966); Chapada, operária, X (ano?) (CMNH 2966); Chapada, 2 operárias, IV (ano ?) highland (CMNH 2966); Serra das Araras, SD-21, 57 $14^{\circ} \mathrm{W}, 1^{\circ} 27^{\prime} \mathrm{S}, 36$ operárias, 19-27.IX.1987, Gimenes col. (RPSP 870911, 870916-870918, 870920, 870921, 870972, 870974-870978, 870980, 870982, 870985, 870986, 870987); Barra do Garças, operária, 14.I.1971, Camargo col. (RPSP); Goiás: Aragarças, 3 operárias, 13.I.1971, Camargo col. (RPSP); Parque Nacional das Emas, operária, VII.1991, A. K. Giovanini col. (RPSP 910780); Minas Gerais: Lontra, 441'' W, $15^{\circ} 06^{\prime}$ 'S, 20 operárias, 17-19.III.1988, Mazucato col. (RPSP 880577-880582, 880595-880599, 880615-880618,

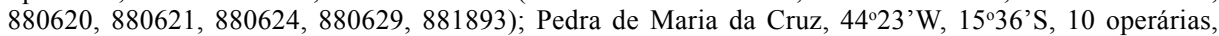
22.VII.1988, Mazucato col. (RPSP 881766, 881795-881797, 881892, 881894-881897, 881899); Gloria (rio?), operária, I (ano ?); 18 operárias, XI (ano?) (CMNH 2966); Mato Grosso do Sul: Corumbá, 112 operárias, IV (ano ?) (MSUC 2966); São Paulo: Teodoro Sampaio, Parque Estadual

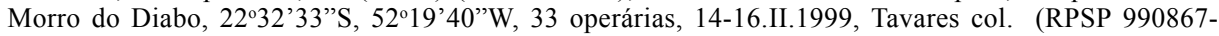
990899); operária, 16.II.1999, F. Zanella col. (RPSP 991817). EQUADOR, Sucumbios: Sacha 

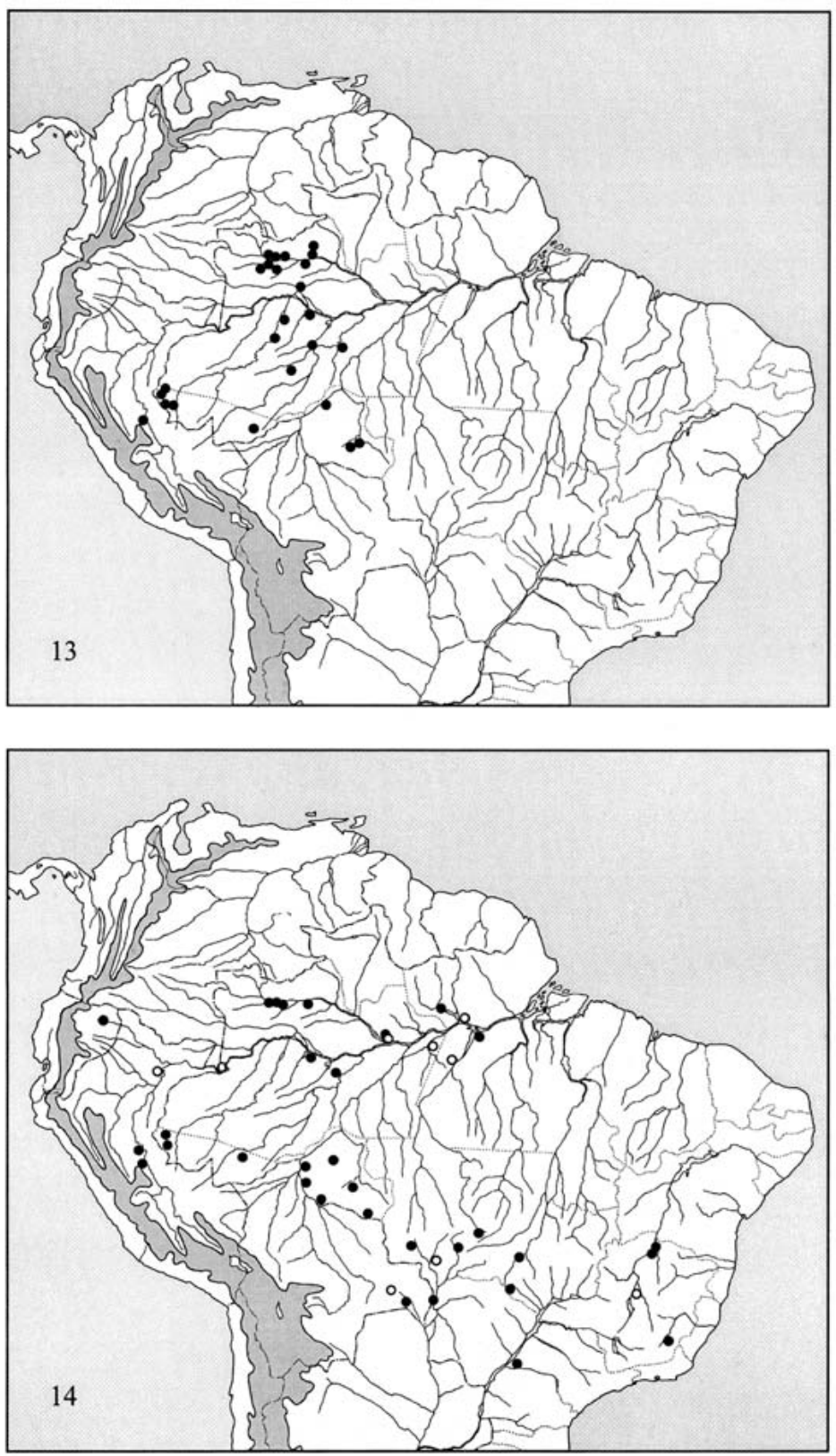

Figs. 13, 14. Distribuição geográfica das espécies de Schwarzula. 13, S. coccidophila sp. nov.; 14, S. timida (Silvestri). Os pontos pretos indicam localidades dos exemplares examinados e os círculos vazados, dados de literatura. 
Lodge, 0,5ㅇ, 76,5 $\mathrm{W}, 270 \mathrm{~m}$, operária, 23.VI-2.VII.1994, malaise, Hibbs col. (SEMC). PERU, Loreto: Pucallpa, 4 operárias, 14.VII.1962, 41 operárias, 16.VII.1962, 14 operárias, 17.VII.1962, operária, 29.VII.1962, operária, 13.VIII.1962, 18 operárias, 18.VIII.1962, W. T. Van Velzen col. (MSUC); Huanuco: R. Pachitea, operária, 01.II.1962, J. M. Shunke col. (RPSP). BOLÍVIA, Santa Cruz: Robore, Prov. Chiquitos, 300m, operária, XI.1959 (MSUC).

Distribuição geográfica. Amazonas até São Paulo, Brasil, Peru, Bolívia e leste do Equador. Além das localidades já citadas, Ducke (1916) mencionou também, Belém, Óbidos, Itaituba (Pará), Manaus, Tabatinga (Amazonas), Jacobina (Mato Grosso), Pirapora (Minas Gerais) no Brasil e Iquitos no Peru. Moure (1950a) citou San José na Bolívia, Maués (Amazonas), Itaituba (Pará) e Porto Cabral (São Paulo) no Brasil, como localidades de ocorrência de S. timida (fig. 14).

Nidificação. Segundo SilveSTRI (1902), em oco de tronco de árvore, em associação com cochonilhas ("lecanite").

Agradecimentos. Aos pesquisadores e curadores, pelo empréstimo de material: Robert W. Brooks e Charles D. Michener (SEMC), Frederick Stehr (MSUC) e John E. Rawlins (CMNH). Ao diretor do INPA, Warwick E. Kerr, e Augusto Loureiro (curador), pelas facilidades concedidas para consulta. Ao ex-diretor do INPA, Ozório J. M. Fonseca e à tripulação do barco UIARA, cuja contribuição foi fundamental para a realização da viagem ao rio Negro em Julho-Agosto, 1999. A Elder F. Morato e Márcio Oliveira (Universidade Federal do Acre), Christopher Brown e Menderson Mazucato, pelo envio de material e coletas, e José Amílcar Tavares Filho, pelo auxílio técnico. À FAPESP, pelo auxílio financeiro, proc. 1998/11605-9.

\section{REFERÊNCIAS BIBLIOGRÁFICAS}

CAmargo, J. M. F. 1988. Meliponinae (Hymenoptera, Apidae) da coleção do "Istituto di Entomologia Agraria", Portici, Itália. Revta bras. Ent., São Paulo, 32(3/4):351-374.

1994. Biogeografia de Meliponini (Hymenoptera, Apidae, Apinae): a fauna amazônica. In: Encontro sobre Abelhas, $1^{\circ}$, Ribeirão Preto, Anais... p. 46-59.

Camargo, J. M. F. \& Moure J. S. 1988. Notas sobre os Meliponinae (Hymenoptera, Apidae) colecionados por Filippo Silvestri na Bacia do Rio da Prata. Revta bras. Ent., São Paulo, 32(2):293-314.

1994. Meliponinae neotropicais: os gêneros Paratrigona Schwarz, 1938 e Aparatrigona Moure, 1951 (Hymenoptera, Apidae). Arq. Zool., São Paulo, 32(2):33-109.

Camargo, J. M. F. \& Pedro, S. R. M. 2002. Mutualistic association between a tiny Amazonian stingless bee and a wax-producing scale insect. Biotropica, St. Louis, 34(3):114-119.

Cruz-Landim, C. \& Mota, M. H. V. B. 1990. Occurrence of tegumentary glands in stingless bees (Hymenoptera, Apidae, Meliponinae). In: International Congress-IUSSI, 11 ${ }^{\circ}$, Bangalore, Proceedings... p. 587,588.

Darchen, R. \& Louis, J. 1961. Les Mélipones et leur Élevage Melipona-Trigona-Lestremelitta [sic]. Annls Abeilles, Paris, 4(I):5-39.

DuCKE, A. 1901. Beobachtungen über Blütenbesuch, Erscheinungszeit etc. der bei Pará vorkommenden Bienen. Z. syst. Hym. Dip., Neubradenburg, 1(2):25-32; 49-67.

1902. Beobachtungen über Blütenbesuch, Erscheinungszeit etc. der bei Pará vorkommenden Bienen. II. Allg. Z. Ent., Berlin, 17:321-326; 360-368; 400-405; 417-422.

- 1916. Enumeração dos hymenopteros colligidos pela Commissão e Revisão das espécies de abelhas do Brasil. 2 ed. Rio de Janeiro, Ministério da Agricultura. 175p., pl.2-7 (Comissão de Linhas Telegráphicas Estratégicas de Matto-Grosso ao Amazonas. Annexo, 5, publicação, 35).

_. 1925. Die stachellosen Bienen (Melipona) Brasiliens; nach morphologischen und ethologischen Merkmalen geordnet. Zool. Jber., Abt. Syst., Jena, 49:335-448, figs A-Z, A’B', pls. 3-4.

Ihering, H. von, 1930. Biologia das abelhas melliferas do Brasil. Bolm Agric. São Paulo, São Paulo, 31:435-506, 649-714 (trad. R. Ihering e B. S. Corrêa). 
Ihering, R. 1968. Dicionário dos Animais do Brasil. São Paulo, Universidade de Brasília. 790p.

Laroca, S. \& Lauer, S. 1973. Adaptação comportamental de Scaura latitarsis para coleta de pólen (Hymenoptera, Apoidea). Acta biol. parana., Curitiba, 2(1,2,3,4):147-152.

Lenko, K. \& Papavero, N. 1996. Insetos no Folclore. 2 ed. rev. ampl. São Paulo, Plêiade, FAPESP. $468 \mathrm{p}$.

Michener, C. D. 1990. Classification of the Apidae (Hymenoptera). Kans. Univ. Sci. Bull., Lawrence, 54(4):75-163.

. 2000. The Bees of the World. Baltimore, The Johns Hopkins University. 913p.

Michener, C. D. \& RoubiK, D. W. 1993. Observations on the labium of Meliponine Bees (Hymenoptera: Apidae). In: Inoue, T. \& Yamane, S. eds. Evolution of Insect Societies: Comparative Sociology of Bees, Wasps and Ants. Tokio, Hakuhin-sha. p.251-265.

Michener, C. D.; Winston, M. L. \& JANDER, R. 1978. Pollen manipulation and related activities and structures in bees of the family Apidae. Kans. Univ. Sci. Bull., Lawrence, 51(19):575-601.

МотA, M. H. V. B. 1992. Estudo comparativo das glândulas epidérmicas do abdômen dos Meliponíneos (Hymenoptera, Apidae, Meliponinae). In: Soares, A. E. E. \& De Jong, D. Pesquisas com abelhas no Brasil. Ribeirão Preto, Revista Brasileira de Genética. p. 320-322.

Moure, J. S. 1946. Contribuição para o conhecimento dos Meliponinae. (Hym. Apoidea). Revta Ent., Rio de Janeiro, 17(3):437-443.

1950a. Notas sobre alguns Meliponinae bolivianos (Hymenoptera, Apoidea). Dusenia, Curitiba, 1(1):70-80.

1950b. Contribuição para o conhecimento das espécies brasileiras de Hypotrigona Cockerell (Hymen.-Apoidea). Dusenia, Curitiba, 1(4):241-260.

1951. Notas sôbre Meliponinae (Hymenopt.-Apoidea). Dusenia, Curitiba, 2(1):25-70.

Nogueira-Neto, P. 1970. A criação de abelhas indígenas sem ferrão. 2. ed. rev. São Paulo, Tecnapis. $365 \mathrm{p}$.

1997. Vida e criação de abelhas indígenas sem ferrão. São Paulo, Nogueirapis. 446p.

Oliveira, M. L. \& Morato, E. F. 1994. Abelhas sem ferrão (Apidae, Meliponinae) do Estado do Acre. In: Encontro sobre Abelhas, $1^{\circ}$, Ribeirão Preto, Anais... p. 291.

Roubik, D. W. \& Moreno, J. E. 2000. Pollen specialization and generalization by stingless bees (Apidae: Meliponini). In: International Conference on Apiculture in Tropical Climates, $6^{\text {th }}$, San Jose, Proceedings... p. 112-118.

Schwarz, H. F. 1932. The genus Melipona: the type genus of the Meliponidae or stingless bees. Bull. Am. Mus. nat. Hist., New York, 63:231-460.

1948. Stingless bees (Meliponidae) of the Western Hemisphere. Lestrimelitta and the folowing subgenera of Trigona: Trigona, Paratrigona, Schwarziana, Parapartamona, Cephalotrigona, Oxytrigona, Scaura, and Mourella. Bull. Am. Mus. nat. Hist., New York, 90:1-546.

Silvestri, F. 1902. Contribuzione alla conoscenza dei Meliponidi del Bacino del Rio de la Plata. Riv. Patol. veg., Portici, 10:121-174, pls. 1-3.

Wille, A. 1979. Phylogeny and relationships among the genera and subgenera of the stingless bees (Meliponinae) of the world. Revta Biol. trop., San José, 27(2):241-277.

1983. Biology of the stingless bees. A. Rev. Ent., Palo Alto, 28:41-64.

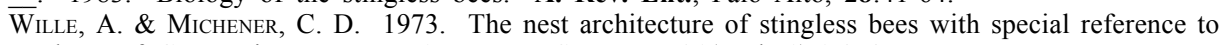
those of Costa Rica. Revta Biol. trop., San José, 21(supl. 1):1-278.

Recebido em 11.10.2001; aceito em 09.08.2002 